\title{
Evaluation of Risk Factors and Management of Neonatal Jaundice in Newborns Admitted in a Tertiary Care Hospital of Rural Haryana
}

\author{
Rupan Deep Kaur ${ }^{1, ~ *, ~ S o n i k a ~ L a m b a ~}{ }^{1}$, Manoj Rawal ${ }^{2}$ \\ ${ }^{1}$ Medicine, Bhagat Phool Singh Government Medical College for Women, Sonepat, India \\ ${ }^{2}$ Paediatrics, Bhagat Phool Singh Government Medical College for Women, Sonepat, India
}

Email address:

rupan.thind@gmail.com (R. D. Kaur), drsonikalamba@gmail.com (S. Lamba), drmanojrawal@yahoo.com (M. Rawal)

${ }^{*}$ Corresponding author

\section{To cite this article:}

Rupan Deep Kaur, Sonika Lamba, Manoj Rawal. Evaluation of Risk Factors and Management of Neonatal Jaundice in Newborns Admitted in a Tertiary Care Hospital of Rural Haryana. American Journal of Pediatrics. Vol. 7, No. 3, 2021, pp. 150-153.

doi: $10.11648 /$ j.ajp.20210703.21

Received: July 15, 2021; Accepted: August 2, 2021; Published: August 9, 2021

\begin{abstract}
Introduction: Neonatal jaundice is one of the most common medical problems in healthy full-term infants during the immediate postnatal period. Neonatal jaundice is the most common cause of readmissions in hospitals in the neonatal period. In low-resource settings, where the majority of births occur outside facilities and access to monitoring and laboratory testing is limited, many of the proven diagnostic and treatment strategies are not available. Aim and objectives: The harmful effects of hyperbilirubinemia can be prevented by early recognition and prompt management of those at risk. This study was aimed to provide information on the risk factors and management associated with neonatal jaundice in a low-resource setting with the objective of identifying potentially modifiable risk factors to reduce the incidence and consequences of jaundice in neonates. Methodology: Patients of Jaundice admitted in pediatrics ward, Bhagat Phool Singh Government Medical College for a period of 4 months formed the sample population. Data included birth weight, gestational age, mother's age, the onset time of hyperbilirubinemia, the onset of breast feeding, history of formula feeding and technique of delivery. Lab data including CBC, bilirubin levels, blood group \& Rh type of mother and neonates. Microsoft word and SPSS software were used for the analysis of the results. Results: Among 100 neonates with neonatal jaundice $19 \%$ of neonates were pre term. 89 neonates were given exclusive breastfeeding. 4 of them were given infant formula powder and the remaining 7 were fed on cow's milk. Gestational age $<37$ weeks was present in 19. Birth weight of 22 neonates was $<2000 \mathrm{~g}$. $77 \%$ of them were born by vaginal delivery and $23 \%$ by caesarean section. In management of neonates, phototherapy was done in 89 neonates, 10 neonates were given conservative treatment and 1 was referred to higher center for exchange transfusion. Conclusion: Several known risk factors for neonatal jaundice were confirmed in this study. It is very essential for health care professionals to be aware of all potential risk factors so that the disease is detected and treated early. The LED phototherapy has decreased the need of exchange transfusion in neonatal jaundice.
\end{abstract}

Keywords: Neonatal, Bilirubin, Jaundice, Phototherapy

\section{Introduction}

Neonatal jaundice is one of the most common medical problems in healthy full-term infants during the immediate postnatal period. Neonatal jaundice affects over half of term $[1,2]$ and $80 \%$ of preterm neonates $[3,4]$ and is the most common cause of readmissions in hospitals in the neonatal period. Jaundice occurs due to increased breakdown of red blood cells and/or impairment in hepatic excretion of bilirubin. Hyperbilirubinemia is our major concern associated with jaundice due to the connection between increased levels of unconjugated bilirubin and neurotoxic effects. [4-6] It has the potential of causing brain damage (kernicterus) with long term neurodevelopmental 
impairment in survivors or death.

Several reports have indicated the major contribution of hyperbilirubinemia to neonatal morbidity and mortality [712]. In a multi-center study in six developing countries, hyperbilirubinemia was a primary diagnosis for severe illness requiring hospital admission, the cause for $12-78 \%$ of the admissions in the first 6 days of life and for $2-57 \%$ of admissions during the next 7-59 days [12]. While the majority of infants have serum levels of $5-6 \mathrm{mg} / \mathrm{dl}$ and will not progress to hyperbilirubinemia, higher levels have been found in exclusively breast-fed infants. [13-15]

In low-resource settings, where the majority of births occur outside facilities and access to monitoring and laboratory testing is limited, many of the proven diagnostic and treatment strategies are not available. Worldwide, an estimated 14.1 million newborns (10.5\% of live births) require phototherapy for jaundice; of these, 6 million do not have access to treatment and 2.4 million without access to treatment are in Central and South Asia. [16] Although phototherapy is effective in the treatment of hyperbilirubinemia, exchange transfusion is occasionally indicated. A nomogram for exchange transfusion based on TSB levels is available. [17] Exchange transfusion should be performed in infants with TSB levels in the range indicated by the nomogram, with TSB levels of $25 \mathrm{mg}$ per dL (427.6 $\mu \mathrm{mol}$ per L) or greater, and with jaundice and signs of acute bilirubin encephalopathy. [17]

The harmful effects of hyperbilirubinemia can be prevented by early recognition and prompt management of those at risk. This study was aimed to provide information on the risk factors and management associated with neonatal jaundice in a low-resource setting with the objective of identifying potentially modifiable risk factors to reduce the incidence and consequences of jaundice in neonates.

\section{Aims and Objective}

To study the various risk factors in newborns with clinical jaundice needing treatment and to assess number of neonates requiring phototherapy \& exchange transfusion in Bhagat Phool Singh Government Medical College for women, Khanpur Kalan, Sonepat from May 2017 to September 2017.

\section{Methodology}

The study was carried out in Department of Pediatrics, at Bhagat Phool Singh Government Medical College for women, Khanpur Kalan, Sonepat.

TYPE OF STUDY: Retrospective study

STUDY POPULATION: All babies born at BPS GMC, Khanpur Kalan Sonepat who were admitted to NICU and postnatal ward, who had clinical jaundice irrespective of the gestational age and birth weight were included in the present study.

SAMPLE SIZE: Patients of Neonatal Jaundice admitted in pediatrics ward for a period of 4 months formed the sample population i.e. 100 patients. Sample size was calculated as follows: (Expected proportion- 93, Precision- 5\%, Desired confidence level- 95\%).

DATA COLLECTION:

Data was collected from case files of baby with neonatal jaundice admitted in Department of Pediatrics. It included birth weight, gestational age, mother's age, the onset time of hyperbilirubinemia, the onset of breast feeding, history of formula feeding and technique of delivery. Frequency of administration of breast milk and the acceptance of feed by the neonate was also noted.

Details of complete physical examination including weight on admission, cephalhematoma, level of consciousness, signs of Kernicterus were included. Lab data including complete blood count $(\mathrm{CBC})$, total serum bilirubin (TSB) including direct and indirect bilirubin, blood group \& $\mathrm{Rh}$ type of mother and neonate were taken in all these neonates to define the cause of hyperbilirubinemia.

Statistical Analysis: Descriptive data was presented as number and percentages. Microsoft word and SPSS software were used for the analysis of the results. A p value of 0.05 or less was considered for statistical significance.

\section{Results}

Among 100 neonates with neonatal jaundice included in the study, $59 \%$ were males and $41 \%$ were females. $19 \%$ of neonates were pre term. 89 neonates were given exclusive breastfeeding. 4 of them were given infant formula powder and the remaining 7 were fed on cow's milk. Gestational age $<37$ weeks was present in 19. Birth weight of 22 neonates was $<2000 \mathrm{~g}$, 56 neonates was $2000-2500 \mathrm{~g}$ and 22 of them had weight ranging from $2500 \mathrm{~g}$ to $2900 \mathrm{~g}$. $77 \%$ of them were born by vaginal delivery and $23 \%$ by caesarean section. 17 of them had bilirubin level $<12 \mathrm{mg} / \mathrm{dl}, 72$ had bilirubin level ranging from $12 \mathrm{mg} / \mathrm{dl}$ to $20 \mathrm{mg} / \mathrm{dl}$ and 11 had bilirubin level $>20 \mathrm{mg} / \mathrm{dl} .12$ newborns had non institutional delivery. 6 of them had birth asphyxia.

In management of neonates, phototherapy was done after covering eyes and genitalia in 89 neonates, 10 neonates were given conservative treatment and 1 was referred to higher center for exchange transfusion.

\section{Discussion}

In our study evaluation of risk factors and management of neonatal jaundice was done. Male preponderance was found to be $59 \%$ which is similar to the study done at Delhi by Singh et al [18], where incidence of hyperbilirubinemia in males was $56.8 \%$. In another study from South India done by Sahoo $\mathrm{M}$ et al [19] male preponderance was $67 \%$. Preterm newborns are more likely to develop jaundice due to immaturity of bilirubin conjugating system, higher rate of hemolysis and increased enterohepatic circulation. [19] The risk of hyperbilirubinemia in preterm is well established in present study as $19 \%$ of cases of neonatal jaundice were preterm. In Study done by Anil Shetty et al [20] $32.9 \%$ were preterm neonates. In an Iranian study by 
Najib et al [21] 90\% neonates were exclusively breast fed. Similar trends were seen in our study where $89 \%$ were exclusively breast fed.

$3.8 \%$ newborns had a history of birth asphyxia in a study conducted in South India by Sahoo M et al [19] which is comparable with our study where incidence came out to be $6 \%$. Other risk factors like low birth weight, non-institutional delivery also show similar pattern with previous studies (Anil Shetty et al). [20]

Phototherapy is effective in most of the cases exchange transfer was required only in 1 case. This is similar to study by Sahoo M et al. [19]

\section{Conclusion}

Several known risk factors for neonatal jaundice were confirmed in this study. It is very essential for health care professionals to be aware of all potential risk factors so that the disease is detected and treated early. The LED phototherapy has decreased the need of exchange transfusion in neonatal jaundice.
Table 1. Analysis of potential risk factors for incident neonatal jaundice.

\begin{tabular}{lc}
\hline SEX & $59 \%$ \\
Males & $41 \%$ \\
Females & \\
BIRTH WEIGHT & $22 \%$ \\
$<2000 \mathrm{~g}$ & $56 \%$ \\
$2000-2500 \mathrm{~g}$ & $22 \%$ \\
$2500-2900 \mathrm{~g}$ & \\
GESTATIONAL AGE & $81 \%$ \\
$>37$ weeks & $19 \%$ \\
$<37$ weeks & \\
EXCLUSIVELY BREAST FED & $89 \%$ \\
Yes & $11 \%$ \\
No & \\
PLACE OF DELIVERY & \\
Institutional & $88 \%$ \\
Non-institutional & $12 \%$ \\
TYPE OF DELIVERY & \\
Vaginal delivery & $77 \%$ \\
Caesarean section & $23 \%$ \\
BIRTH ASPHYXIA & \\
Present & $6 \%$ \\
Absent & $94 \%$ \\
\hline
\end{tabular}

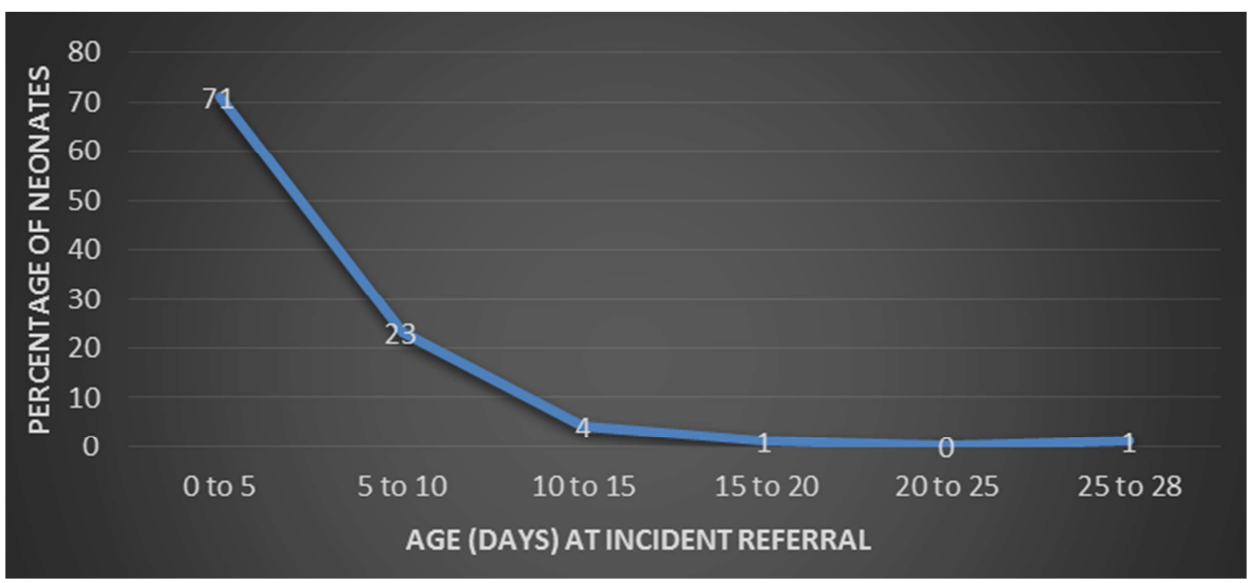

Figure 1. Age distribution of neonates with NNJ.

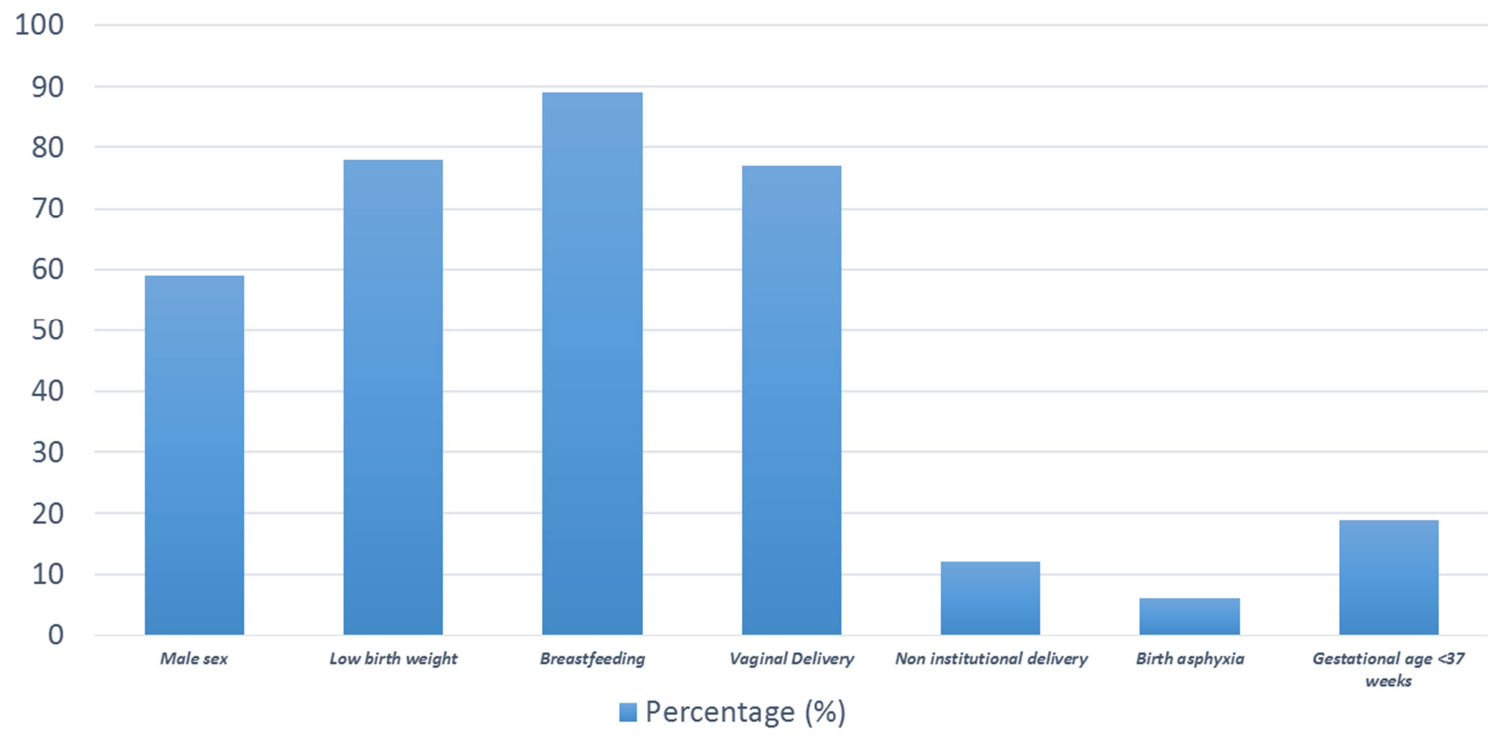

Figure 2. Association of risk factors with neonatal jaundice. 


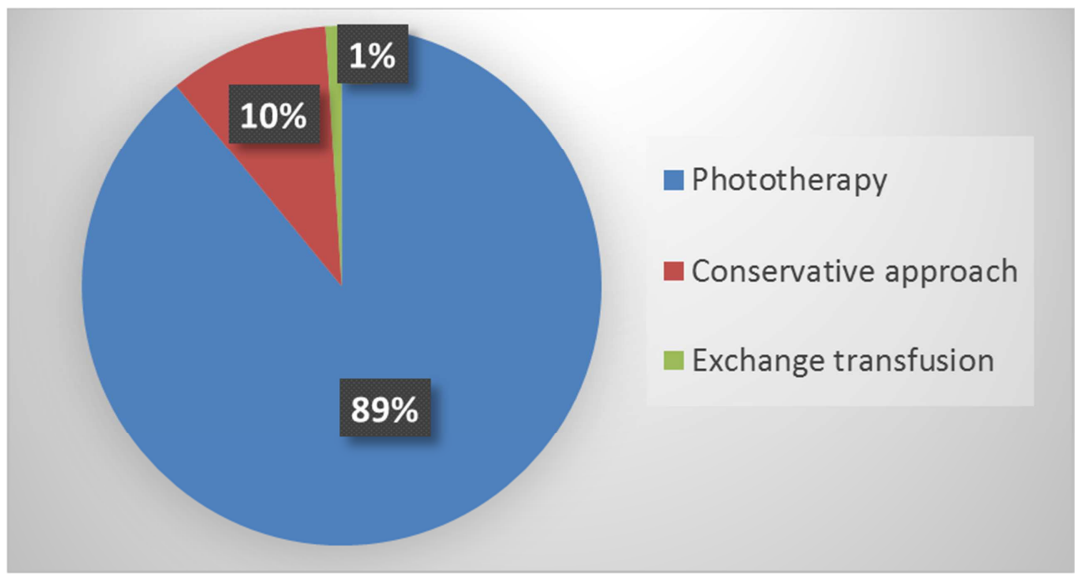

Figure 3. Management of Neonatal jaundice.

\section{References}

[1] Cohen SM. Jaundice in the full-term newborn. Pediatr Nurs. 2006 May-Jun; 32 (3): 202-208.

[2] Sarici SU, Serdar MA, Korkmaz A, Erdem G, Oran O, Tekinalp $\mathrm{G}$, et al. Incidence, course, and prediction of hyperbilirubinemia in near-term and term newborns. Pediatrics. 2004 Apr; 113 (4): 775-780.

[3] Newman TB, Xiong B, Gonzales VM, Escobar GJ. Prediction and prevention of extreme neonatal hyperbilirubinemia in a mature health maintenance organization. Arch Pediatr Adolesc Med. 2000 Nov; 154 (11): 1140-1147.

[4] Watchko JF. Identification of neonates at risk for hazardous hyperbilirubinemia: emerging clinical insights. Pediatr Clin North Am. 2009 Jun; 56 (3): 671-87. Table of Contents.

[5] Beachy JM. Investigating jaundice in the newborn. Neonatal Netw. 2007 Sep-Oct; 26 (5): 327-333.

[6] Watchko JF. Kernicterus and the molecular mechanisms of bilirubin-induced CNS injury in newborns. Neuromolecular Med. 2006; 8 (4): 513-529.

[7] Maisels MJ, Kring E. Length of stay, jaundice, and hospital readmission. Pediatrics. 1998 Jun; 101 (6): 995-998.

[8] Seidman DS, Stevenson DK, Ergaz Z, Gale R. Hospital readmission due to neonatal hyperbilirubinemia. Pediatrics. 1995 Oct; 96 (4 Pt 1): 727-729.

[9] Hameed NN, Na'Ma AM, Vilms R, Bhutani VK. Severe neonatal hyperbilirubinemia and adverse short-term consequences in Baghdad, Iraq. Neonatology. 2011; 100 (1): 57-63.

[10] Olusanya BO, Akande AA, Emokpae A, Olowe SA. Infants with severe neonatal jaundice in Lagos, Nigeria: incidence, correlates and hearing screening outcomes. Trop Med Int Health. 2009 Mar; 14 (3): 301-310.

[11] Sgro M, Campbell D, Barozzino T, Shah V. Acute neurological findings in a national cohort of neonates with severe neonatal hyperbilirubinemia. J Perinatol. 2011 Jun; 31 (6): 392-396.

[12] Young Infants Clinical Signs Study Group. Clinical signs that predict severe illness in children under age 2 months: a multicentre study. Lancet. 2008 Jan 12; 371 (9607): 135-142.

[13] Ip S, Chung M, Kulig J, O’Brien R, Sege R, Glicken S, et al. An evidence-based review of important issues concerning neonatal hyperbilirubinemia. Pediatrics. 2004 Jul; 114 (1): e130-53.

[14] Maisels MJ. What's in a name? Physiologic and pathologic jaundice: the conundrum of defining normal bilirubin levels in the newborn. Pediatrics. 2006 Aug; 118 (2): 805-807.

[15] Maisels MJ, Bhutani VK, Bogen D, Newman TB, Stark AR, Watchko JF. Hyperbilirubinemia in the newborn infant $>$ or $=35$ weeks' gestation: an update with clarifications. Pediatrics. 2009 Oct; 124 (4): 1193-1198.

[16] Bhutani VK. Editorial: building evidence to manage newborn jaundice worldwide. Indian J Pediatr. 2012 Feb; 79 (2): 253255.

[17] American Academy of Pediatrics Subcommittee on Hyperbilirubinemia. Management of hyperbilirubinemia in the newborn infant 35 or more weeks of gestation [published correction appears in Pediatrics. 2004; 114 (4): 1138]. Pediatrics. 2004; 114 (1): 297-316.

[18] Singhal PK, Singh M, Paul VK, Deorari AK, Ghorpade MG. Spectrum of neonatal hyperbilirubinemia: an analysis of 454 cases. Indian Pediatr. 1992 Mar; 29 (3): 319-25. [PubMed]

[19] Sahoo M, Arigela V, L Pramitha, Sudarsini P, Rao KU. Study of neonatal jaundice in a tertiary care centre of South India. Int J Pediatr Res. 2016; 3 (8): 589-592. doi: 10.17511/ijpr.2016.8.07

[20] Shetty A, Kumar BS. A study of neonatal hyperbilirubinemia in a tertiary care hospital. Int J Med Sci Public Health 2014; 3: $1289-1292$.

[21] Najib KS, Saki F, Hemmati F, Inaloo S. Incidence, Risk Factors and Causes of Severe Neonatal Hyperbilirubinemia in the South of Iran (Fars Province). Iran Red Cres Med J. 2013; 15 (3): 260-3. DOI: $10.5812 /$ ircmj.3337. 